\title{
Types of neural guides and using nanotechnology for peripheral nerve reconstruction
}

This article was published in the following Dove Press journal:

International Journal of Nanomedicine

9 October 2010

Number of times this article has been viewed

\section{Esmaeil Biazar' \\ MT Khorasani ${ }^{2}$ \\ Naser Montazeri ${ }^{1}$ \\ Khalil Pourshamsian' \\ Morteza Daliri ${ }^{3}$ \\ Mostafa Rezaei $\mathrm{T}^{4}$ \\ Mahmoud Jabarvand $\mathrm{B}^{5}$ \\ Ahad Khoshzaban ${ }^{5}$ \\ Saeed Heidari $\mathrm{K}^{4,5}$ \\ Mostafa Jafarpour 6 \\ Ziba Roviemiab ${ }^{7}$ \\ 'Department of Chemistry, Islamic Azad University-Tonekabon Branch, Iran; ${ }^{2}$ Biomaterial Department of Iran Polymer and Petrochemical Institute, \\ Tehran, Iran; ${ }^{3}$ National Research \\ Center for Genetic Engineering and Biotechnology, Tehran, Iran; ${ }^{4}$ Proteomics Research Center, Faculty of Paramedical Sciences, Shaheed Beheshti University of Medical Sciences, Tehran, Iran; ${ }^{5}$ Eye Research Center, Farabi Eye Hospital, Tehran University of Medical Sciences, Tehran, Iran; ${ }^{6}$ Department of Microbiology, Islamic Azad University-Tonekabon Branch, Iran; ${ }^{7}$ Biomedical Engineering Faculty, Islamic Azad University- Science and Research Branch, Tehran, Iran}

Correspondence: Esmaeil Biazar Islamic Azad University, Tonekabon Branch, Mazandaran, Iran Tel +98 1924274415

Fax +98 I92 42744 II

Email e.biazar@tonekaboniau.ac.ir
Abstract: Peripheral nerve injuries can lead to lifetime loss of function and permanent disfigurement. Different methods, such as conventional allograft procedures and use of biologic tubes present problems when used for damaged peripheral nerve reconstruction. Designed scaffolds comprised of natural and synthetic materials are now widely used in the reconstruction of damaged tissues. Utilization of absorbable and nonabsorbable synthetic and natural polymers with unique characteristics can be an appropriate solution to repair damaged nerve tissues. Polymeric nanofibrous scaffolds with properties similar to neural structures can be more effective in the reconstruction process. Better cell adhesion and migration, more guiding of axons, and structural features, such as porosity, provide a clearer role for nanofibers in the restoration of neural tissues. In this paper, basic concepts of peripheral nerve injury, types of artificial and natural guides, and methods to improve the performance of tubes, such as orientation, nanotechnology applications for nerve reconstruction, fibers and nanofibers, electrospinning methods, and their application in peripheral nerve reconstruction are reviewed.

Keywords: peripheral nerve injuries, nerve reconstruction, neural guide, nanofibers

\section{Introduction}

Peripheral nerves form an extensive network that links the brain and spinal cord to all other parts of the body. Peripheral nerves are fragile and easily damaged. A nerve injury can interfere with communication between the brain and the muscles controlled by a nerve, affecting a person's ability to move certain muscles or have normal sensations. Several hundreds of thousands of such traumatic injuries occur each year in Europe and the US alone. A peripheral nerve, when severed, is capable of a substantial amount of regeneration. The peripheral nerve contains only the axon part of the neuron and one could consider the peripheral nerve trunk as a protective structure for axons. The cell bodies of sensory neurons are located in the structures just next to the spinal cord, ie, the dorsal root ganglia, or in the cranial ganglia, while the cell bodies of the motor neurons are located within the central nervous system (spinal cord or brainstem). Regenerating axons are accurately guided for long distances along naturally occurring bands of Bungner when the nerve defect is bridged. The most popular approach in peripheral nerve tissue engineering involves in vivo implantation of artificial scaffolds and substrates that will guide naturally regenerating axons to the distal segment. Peripheral nerves are discrete trunks filled with sensory and motor axons, and support a number of cell types, such as Schwann cells and fibroblasts. Due to limb movements and the resulting tensile and 
compressive stresses, the epineurium provides a protective structure for the axons. The epineurium is a sheath of loose fibrocollagenous tissue that binds individual fascicles into one nerve trunk. Inside these fascicles are the axons, myelinated by Schwann cells. ${ }^{1-3}$ Peripheral spinal nerves originate from the dorsal or ventral roots of the spinal cord, while cranial nerves originate from the brainstem. The dorsal roots contain sensory axons and carry signals into the central nervous system, while the ventral roots carry motor signals from neurons originating in the central nervous system to muscles and glands (Figure 1). Cranial nerves can be purely sensory or motor, or may contain both types of axons. ${ }^{4,5}$

Reconstruction of damaged nerves results from different factors that have been investigated by different methods. This paper reviews a number of methods, such as utilizing allograft techniques, ${ }^{6}$ cell therapy including Schwann cells, ${ }^{7}$ stem cells, fibroblasts, and olfactory cells, or drug therapy, use of biologic tubes, designed scaffolds with synthetic and natural materials and oriented channels, and absorbable and nonabsorbable synthetic and natural polymers with unique features benefiting from new nanotechnology, capable of improving the performance of strategies to repair damaged nerve tissue.

\section{Types of nerve guides Autologous nerve guides}

Peripheral nerve injuries most commonly result from blunt trauma or from penetrating missiles such as bullets or other objects, but are also associated with fractures and fracture dislocations. Therefore, crush injuries are more common

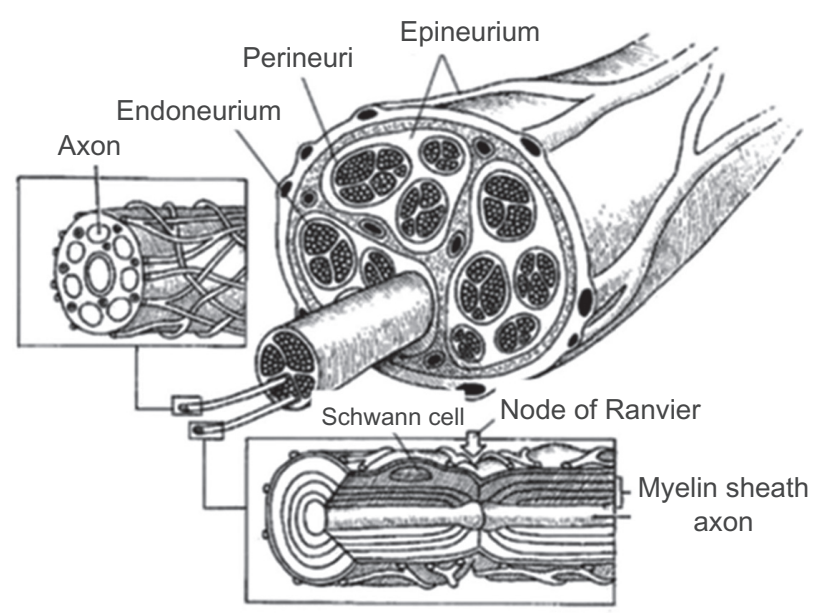

Figure I Cross-sectional anatomy of a peripheral nerve. Inset at left shows an unmyelinated fiber. Inset at bottom shows a myelinated fiber. than nerve transections. When nerve endings are unable to be rejoined without tension, a bridging section of nerve is used and two end-to-end sutures are performed. The crushed section of the nerve is cut, removed, and replaced by a nerve taken from another (less important) site, typically the sural nerve at the back of the leg. ${ }^{8}$

The autograft works relatively well in practice, and is the gold standard upon which all alternative therapies are judged. However, a second surgery is required to obtain the bridging nerve, and there is loss of function at the donor site, often leading to detrimental changes, such as scarring and the possible formation of painful neuromas. Furthermore, donor nerves are often of small caliber and limited in number. These problems drive the search for a tissue engineering alternative to this treatment. ${ }^{8}$

\section{Biologic nerve guides}

Weiss used non-nerve tissues as alternatives to suture repair of a nerve to bridge very short nerve gaps successfully. ${ }^{7-11}$ Since then, conduits from many different biologic tissues have been used with varying success. These include the use of arteries, ${ }^{10,11}$ veins, ${ }^{12-14}$ muscles, ${ }^{15-18}$ and other materials which are extensively reviewed by Doolabh et al. ${ }^{19}$ Other nerve tube conduits have been made from modified biologic tissues such as lami$\operatorname{nin}^{19}$ and collagen, ${ }^{20,21}$ and have proved successful in specific situations. There are a number of disadvantages with the use of blood vessel, muscle, and other biologic tissues in bridging peripheral nerve defects, including tissue reaction, early fibrosis, scar infiltration, and lack of precise control of the conduit's mechanical properties. ${ }^{19}$ These limitations have led to the emergence of conduits made from novel synthetic materials, despite potential problems with biocompatibility. Figure 2 shows guide types that are used for nerve regeneration.

\section{Synthetic nerve guides Nonabsorbable artificial nerve guides}

Beginning in the early 1980s, replacement surgery using artificial nerve conduits made from nonabsorbable materials, such as silicone (Figure 3), has been in use for the treatment of severed nerves, and there are reports documenting partial recoveries with the technique. All these reports, however, are of studies demonstrating recovery in morphologic continuity of a nerve with an extremely small gap of about $10 \mathrm{~mm}$ in small laboratory animals, and recovery of motor function has rarely been achieved. The outcome is in no way superior to that of nerve autografting in any of the reported studies. $^{22-25}$ 


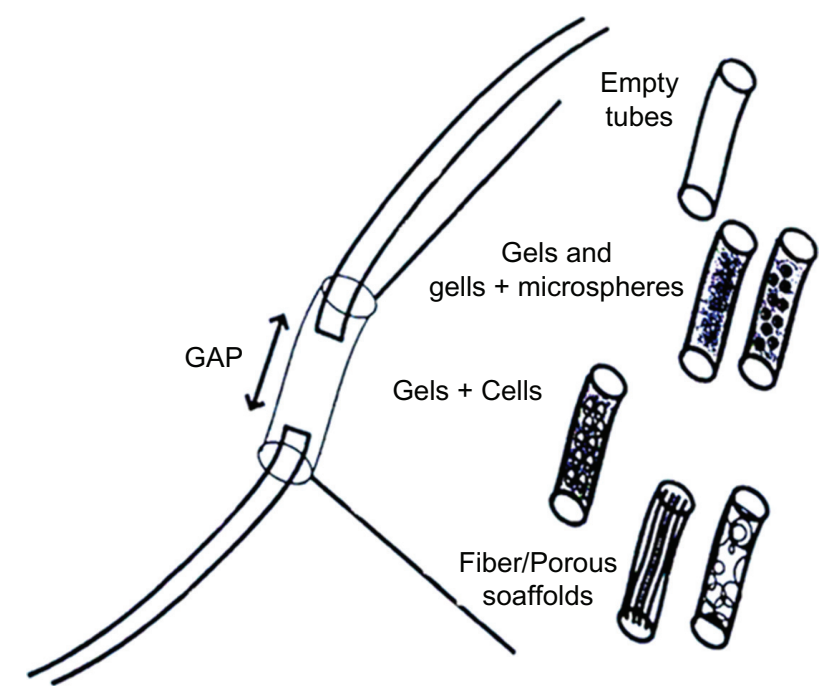

Figure $\mathbf{2}$ Tubes or guide types for peripheral nervous system regeneration.

\section{Absorbable artificial nerve guides}

It became recognized from the latter half of the 1980s onwards that degradable-absorbable materials are preferable in the body after attaining nerve regeneration. ${ }^{26}$ With the progress in material synthesis and bridging techniques, artificial nerve conduits made of absorbable synthetic materials have been developed. Substances such as polyglycolic acid (PGA) and polylactic acid (PLA) or polyhydroxybutyrate ${ }^{26}$ (Figure 4) are under investigation as biodegradable-absorbable synthetic materials for nerve regeneration. ${ }^{26}$ The absorbable and nonabsorbable synthetics such as PLA, PGA, and the copolymer, poly lactic-co-glycolic acid (PLGA), have been widely used for nerve regeneration. All three polymers have been approved by the Food and Drug Administration for use

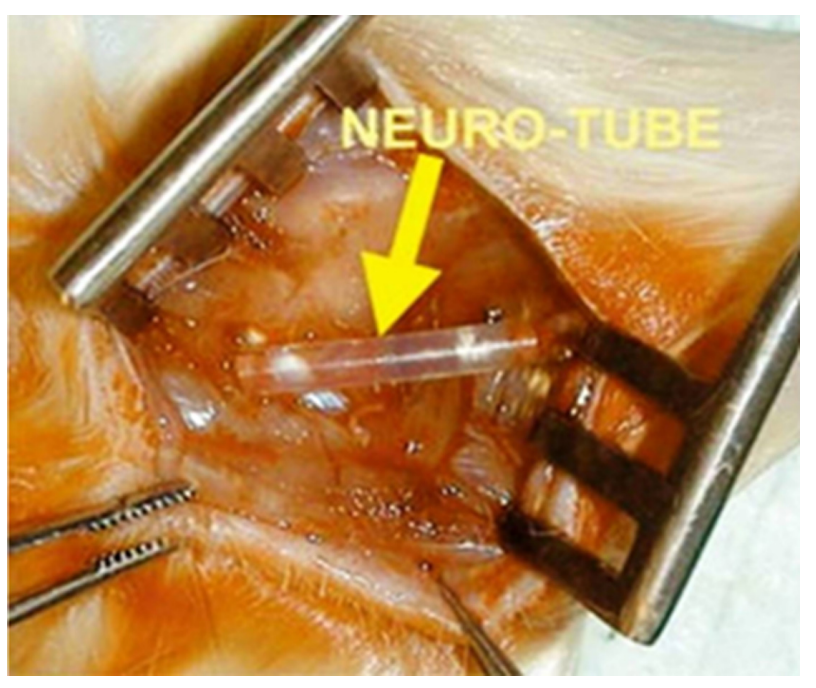

Figure 3 Silicone tube for nerve regeneration. in various devices. These polymers are brittle, and they do not have regions permissible for chemical modification. In addition, they degrade by bulk rather than by surface, which is not a smooth and ideal degradation process. In an attempt to overcome the lack of functionality, free amines have been incorporated into their structures from which peptides can be tethered to control cell attachment and behavior. ${ }^{26}$ Khorasani et al have designed PLA tubes for nerve regeneration, done cellular investigations, and made in vitro assessments. ${ }^{27,28}$

\section{Artificial absorbable nerve guides made of natural materials}

Since the beginning of the 1990s, there have been several published studies reporting that natural collagen is satisfactory as a biomaterial for regeneration of various tissues and/or organs and that it is also useful for peripheral nerve regeneration. Thus, comparative experiments with artificial nerve conduits comprising collagen extract alone versus autologous nerve grafting were performed. The results of the research with conduits were comparable with those of nerve autografting, and the regenerated nerves were found to be much inferior to intact nerves. Chitosan and chitin belong to a family of biopolymers composed of $\beta(1-4)$-linked N-acetyl-D-glucosamine and D-glucosamine subunits. Figure 5 shows chitosan guides to be absorbable natural materials when used for nerve regeneration.

Prang et al assessed the capacity of alginate gels to promote directed axonal regrowth in the injured mammalian central nervous system. Multivalent copper ions were used to create the alginate-based gels, diffusion of which into the sodium alginate layers created hexagonally-structured anisotropic capillary gels. After precipitation, the entire gel was traversed by longitudinally-oriented capillaries. The alginate scaffolds promoted adult peripheral nerve survival and highly oriented axon regeneration. ${ }^{30}$ This was the first instance of using alginates to produce anisotropic-structured capillary gels.

Further studies are needed to investigate the long-term physical stability of the alginate scaffolds, because central nervous system axon regeneration can take many months to occur. However, in addition to being able to provide longterm support, the scaffolds must also be degradable. Of all the biologic and synthetic biopolymers investigated by Prang, only agarose-based gels were able to be compared with the linear regeneration achieved by alginate scaffolds. Future studies will also need to investigate whether the alginate scaffolds allow for reinnervation of the nerve target in vivo after a spinal cord injury. ${ }^{30}$ 

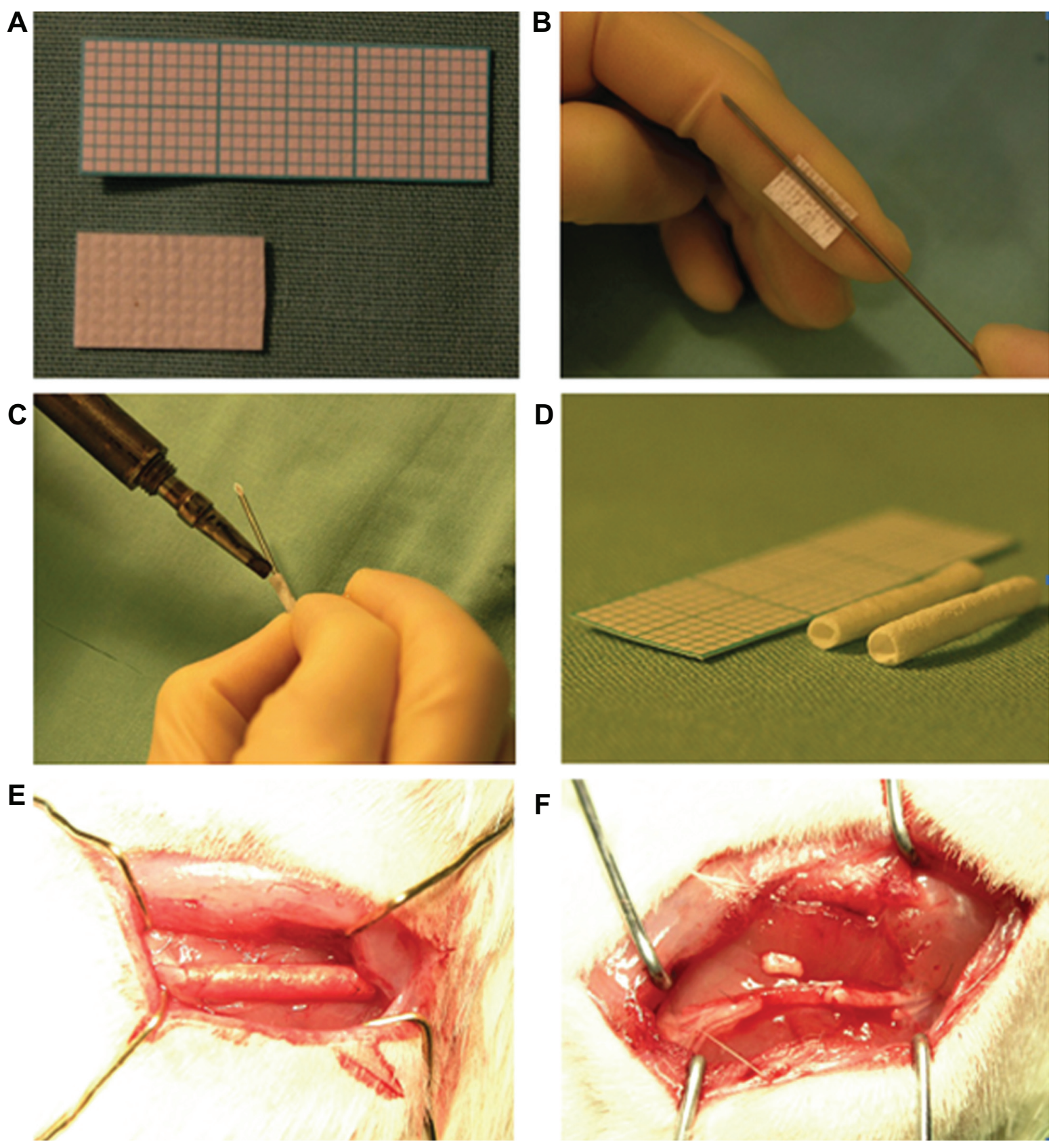

Figure 4 Polyhydroxybutyrate conduit preparation. A) Polyhydroxybutyrate material is manufactured as a sheet that can be cut to measure of any size. B) Polyhydroxybutyrate sheet is rolled around a 16 gauge needle. C) Heat sealing of the rolled conduit. D) Rolled and sterilized conduits ready to be implanted. E) Implanted polyhydroxybutyrate conduit at the sciatic nerve site. F) Implanted polyhydroxybutyrate strip at the sciatic nerve site.

Collagen is the major component of the extracellular matrix and has been widely used in nerve regeneration and repair. Collagen Type I/III scaffolds have demonstrated good biocompatibility and are able to promote Schwann cell proliferation. However, collagen conduits, filled with Schwann cells and used to bridge nerve gaps in rats, have shown surprisingly unsuccessful nerve regeneration compared with nerve autografts. This is because biocompatibility is not the only factor necessary for successful nerve regeneration. Other parameters, such as inner diameter, inner microtopography, porosity, wall thickness, and Schwann cell seeding density, will need to be examined in future studies in order to improve the results obtained by these collagen Type I/III gels. ${ }^{31}$

Polysialic acid (PSA) is a relatively new biocompatible and bioresorbable material for artificial nerve conduits. PSA shows stability under cell culture conditions and allows for degradation induced by enzymes. It has also been discovered recently that PSA is involved in steering processes like neuritogenesis, 


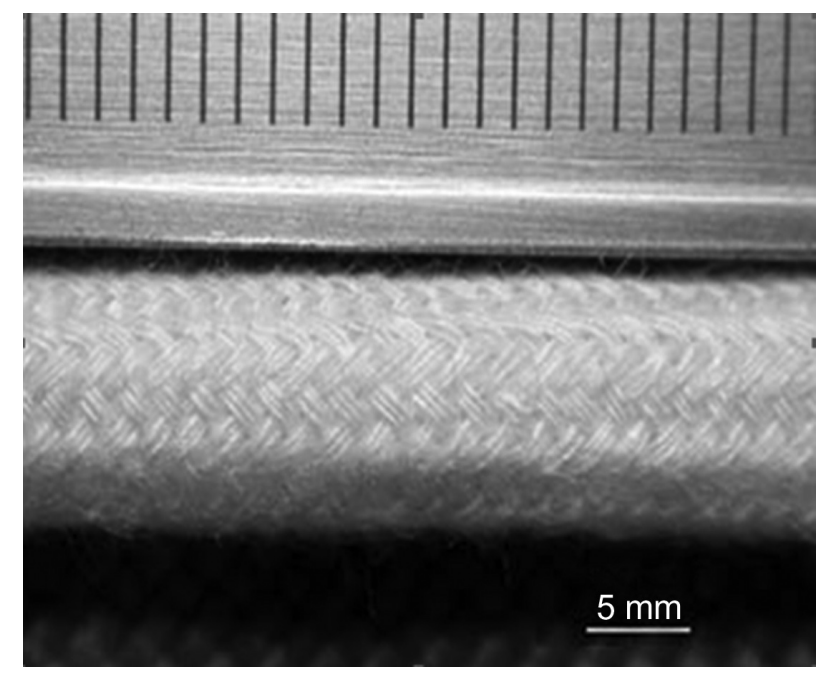

Figure 5 Representative photomicrograph of braided chitosan hollow tubes made from chitosan yarns through an industrial braiding technique.

axonal path finding, and neuroblast migration. Animals with PSA genetically knocked out express a lethal phenotype which has unsuccessful path finding, ie, the nerves connecting the two brain hemispheres are aberrant or missing. Thus, PSA is vital for proper nervous system development. ${ }^{32}$

\section{Composite nerve guides}

The best materials for designing a scaffold are possibly both synthetic and natural polymers. Natural polymers, such as chitosan, alginate, and especially collagen and fibrin, due to their structural similarity with the neural structure, and properties such as cell attachment have better advantages than synthetic polymers, but design considerations and their propensity to swell is problematic in the widespread use of such materials. However, designs with small nerve gaps have been responsive. Utilizing synthetic polymers because of the design control and the use of natural polymers, either spongy or fibrous, and oriented porous or hydrogel and other forms and/or coated, can show better function for neural reconstruction. Japanese researchers using polymeric PGA mesh and collagen sponge inside the tube could reconstruct a peripheral nerve gap of about $3 \mathrm{~cm} \cdot .^{32,33}$ This structure is shown in Figure $6 .^{33}$

\section{Types of neural structures}

A superstructure is a structure or a cellular scaffold for tissue simulation. The ways of forming synthetic superstructures include the use of hydrogels responding to environmental stimuli such as heat or the formation of ordered longitudinal channels or fibers, and also tensile axons and nanofibrous structures. ${ }^{34}$

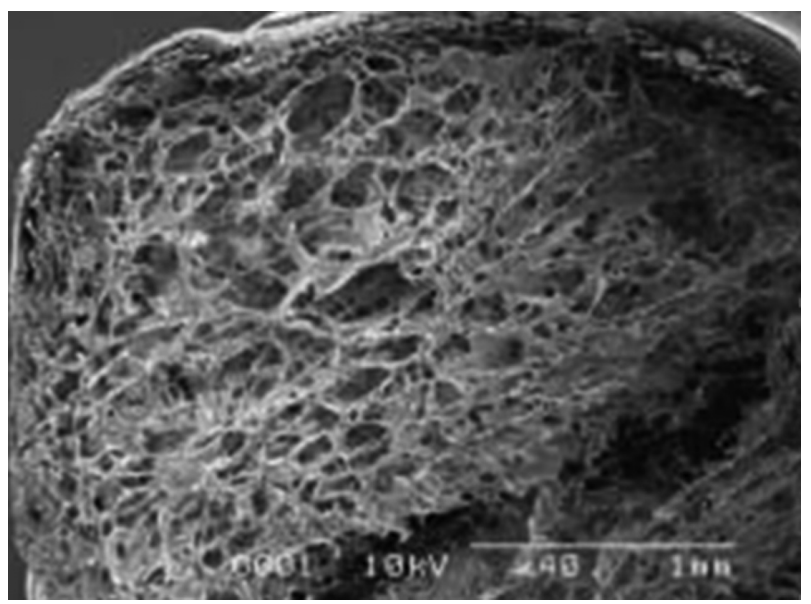

Figure 6 Electron micrograph of a poly glycolic acid (PGA)-collagen composite nerve conduit filled with collagen sponge. The PGA-collagen composite conduit is filled with a three-dimensional sponge matrix.

\section{Longitudinally oriented guides}

Longitudinally oriented channels are macroscopic structures that can be added to a conduit in order to give the regenerating axons a well-defined guide for growing straight along the scaffold. In a scaffold with microtubular channel architecture, regenerating axons are able to extend through open longitudinal channels in the manner in which they would normally extend through the endoneural tubes of peripheral nerves. Additionally, the channels increase the surface area available for cell contact. The channels are usually created by inserting a needle, wire, or second polymer solution within a polymer scaffold. After stabilizing the shape of the main polymer, the needle, wire, or the second polymer is removed in order to form the channels. Typically, multiple channels are created; however, the scaffold can consist of just one large channel, which is simply one hollow tube. ${ }^{34}$ Figure 7 shows the method of preparation for oriented structures using chemical processes. Oriented structures are created by copper cations. Such oriented structures are used for nerve repair. ${ }^{34}$

A molding technique was created by Wang et al for forming a nerve guidance conduit with a multichannel inner matrix and an outer tube wall from chitosan. ${ }^{35}$ In their 2006 study, using threaded acupuncture needles through a hollow chitosan tube held in place by fixing at on either end, the patches were created using CAD. A chitosan solution was then injected into the tube and was solidified, after which the needles were removed, creating longitudinally oriented channels. A representative scaffold was then created for characterization, with 21 channels using acupuncture needles of $400 \mu \mathrm{m}$ in diameter. Upon investigation under a 

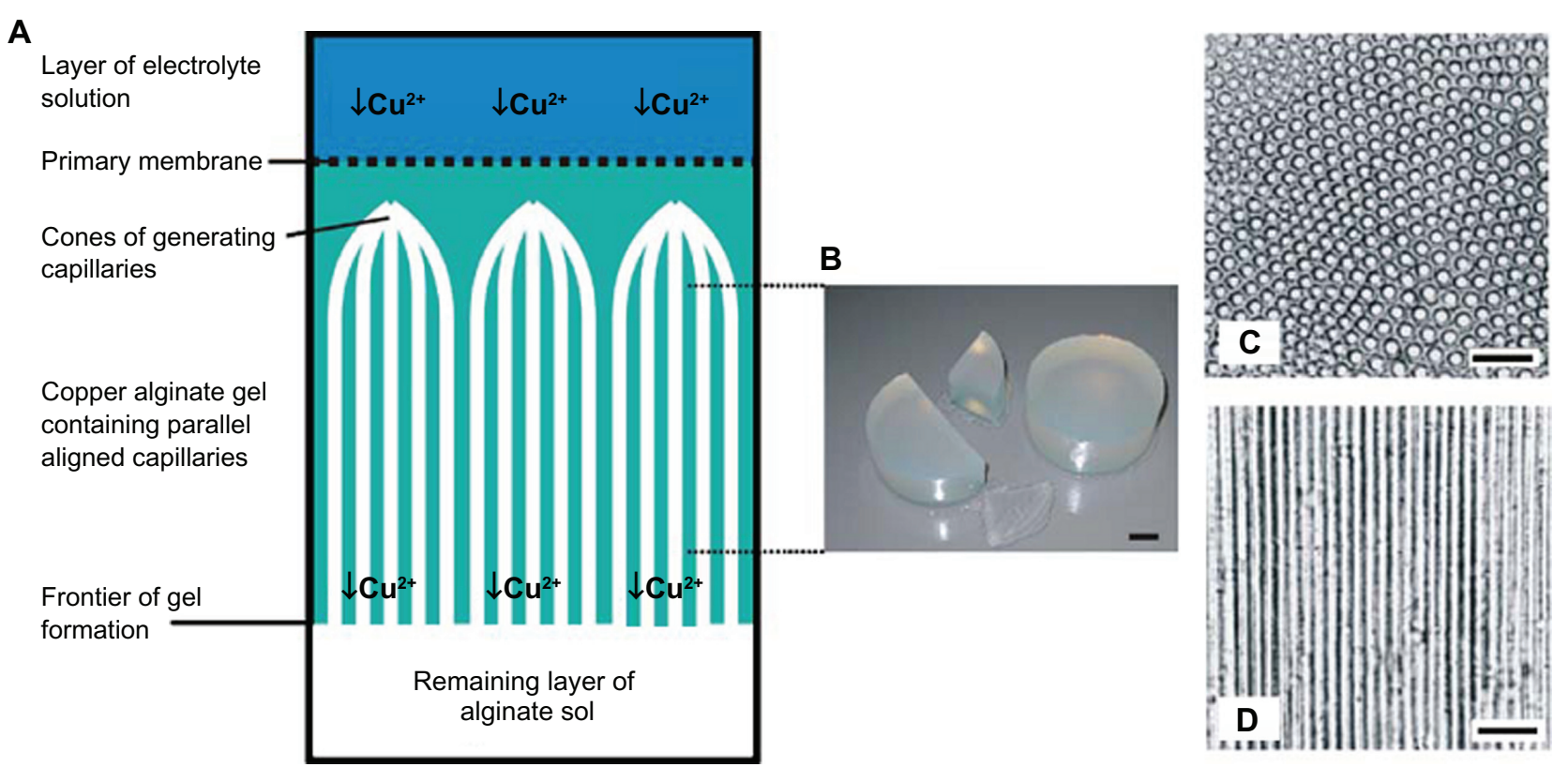

Figure 7 Ultrastructure of alginate-based anisotropic capillary gels (ACH). A) Illustration of the different phases of anisotropic capillary gel formation. B) Macroscopic appearance of $\mathrm{ACH}$ bodies. C) $\mathrm{ACH}$ in cross- and $\mathbf{D}$ ) longitudinal sections. Scale: $\mathbf{B ~} \mathrm{I} \mathrm{cm}, \mathbf{C} 100 \mathrm{~mm}$, and $\mathbf{D} 100 \mathrm{~mm}$.

microscope, the channels were found to be approximately circular with slight irregularities, and all channels were aligned with the inner diameter of the outer tube wall. It was confirmed by microcomputed tomography imaging that the channels went through the entire length of the scaffold. Under water absorption, the inner and outer diameters of the scaffold became larger, but the channel diameters did not vary significantly, which was necessary for maintaining the scaffold shape that guided neurite extension. The inner structure provided an increase in compressive strength compared with a hollow tube alone, which could prevent the collapse of the scaffold onto growing neurites. Cells from a neuro-2a cell line were able to grow on the inner matrix of the scaffold, and were oriented along the channels. Although this method has only been tested on chitosan, it can be tailored to other materials.

Lyophilizing and wire-heating process are other methods of creating longitudinally-oriented channels developed by Huang et al. A chitosan and acetic acid solution was frozen around nickel-copper wires in a liquid nitrogen trap; subsequently, the wires were heated and removed. Nickel-copper wires were chosen because they had a high resistance level. Temperature-controlled lyophilizers were used to sublime the acetic acid. There was no evidence of the channels merging or splitting. After lyophilizing, the scaffold dimensions shrank, causing the channels to be a bit smaller than the wire used. The scaffolds were neutralized to a physiologic $\mathrm{pH}$ value using a base, which had dramatic effects on the porous structure. Weaker bases kept the porous structure uniform, but stronger base made it uncontrollable. The technique used here can be slightly modified to accommodate other polymers and solvents. ${ }^{36}$

Another way to create longitudinally oriented channels is to create a conduit from one polymer with embedded longitudinally oriented fibers from another polymer, and then selectively dissolve the fibers to form longitudinally oriented channels. Polycaprolactone (PCL) fibers were embedded in a hydroxyethylmethacrylate (HEMA) scaffold. PCL was chosen in preference to PLA and PLGA because it was insoluble in HEMA but soluble in acetone. This is important because HEMA was used for the main conduit material and acetone was used to dissolve the polymer fibers selectively. Extruded PCL fibers were inserted into a glass tube and the HEMA solution was injected. The number of channels created was consistent from batch to batch and the variations in fiber diameter could be reduced by creating a more controlled PCL fiber extrusion system. The channels formed were confirmed to be continuous and homogeneous by examination of porosity variations. This process is safe, reproducible, and has controllable dimensions.

In a similar study conducted by Yu et al HEMA was copolymerized with ethyl methacrylamide (AEMA) to create a P(HEMA-co-AMEA) gel. ${ }^{37}$ PCL fibers were embedded in the gel, and then selectively dissolved by acetone with sonication to create channels. It was found that HEMA in a mixture with $1 \%$ AEMA created the strongest gels. 
When compared with scaffolds without channels, the addition of 82-132 channels could provide an approximately 6-9 fold increase in surface area, which might be advantageous for regeneration studies that depended on contactmediated cues. ${ }^{37}$ Itoh et al developed a scaffold consisting of a single large longitudinally oriented channel that was created using chitosan tendons from crabs. The tendons were harvested from crabs (Macrocheira kaempferi) and were repeatedly washed with sodium hydroxide solution to remove proteins and to deacetylate the tendon chitin, which subsequently became known as tendon chitosan. A stainless steel bar with a triangular-shaped cross-section (each side $2.1 \mathrm{~mm}$ long) was inserted into a hollow tendon chitosan tube of circular-shaped cross-section (diameter $2 \mathrm{~mm}$, length $15 \mathrm{~mm}$ ). When comparing the circular-shaped and triangular-shaped tubes, it was found that the triangular tubes had improved mechanical strength, held their shape better, and increased the surface area available. While this is an effective method for creating a single channel, it does not provide as much surface area for cellular growth as the multichannel scaffolds. ${ }^{38}$

\section{Longitudinally oriented fibers}

In addition to longitudinally oriented channels, longitudinallyoriented fibers can also be added to a conduit to provide regenerating axons with guidance for longitudinally directed growth. Studies conducted by Newman et $\mathrm{al}^{39}$ and Cai et $\mathrm{al}^{40}$ showed that adding filaments to a scaffold promotes inner contact guidance and increases permeability for better nutrient and waste exchange, such that the scaffold has superior nerve repair performance over nonpermeable conduits that lack filaments. Newman et al inserted conductive and non-conductive fibers into a collagen-TERP scaffold (collagen cross-linked with a tetrapolymer of poly $(\mathrm{N}$ isopropylacrylamide). The fibers were embedded by tightly wrapping them on a small glass slide and sandwiching a collagen-TERP solution between it and another glass slide, and spacers between the glass slides set the gel thickness to $800 \mu \mathrm{m}$. The conductive fibers were carbon fiber and Kevlar $^{\circledR}$, and the nonconductive fibers were nylon-6 and tungsten wire. Neurites were extended in all directions in thick bundles on the carbon fiber but, with the other three fibers, neurites were extended in fine web-like conformations. The neurites showed no directional growth on the carbon and Kevlar fibers, but they grew along the nylon- 6 fibers and to some extent along the tungsten wire. The tungsten wire and nylon-6 fiber scaffolds had neurites growing into the gel near the fiber-gel interface, in addition to growing along the surface. All fiber gels except Kevlar showed a significant increase in neurite extension compared with nonfiber gels. There was no difference in neurite extension between the nonconductive and the conductive fibers. ${ }^{39}$ Cai et al added poly L-lactic acid microfilaments to hollow PLA and silicon tubes. The microfiber guidance characteristics were inversely related to the fiber diameter, with smaller diameters promoting better longitudinally oriented cell migration and axonal regeneration. The microfibers also promoted myelination during peripheral nerve repair. ${ }^{40}$

\section{Oriented matrices}

In vivo experiments with oriented matrices have a higher growth value than isotropic matrices of the same material. Various cells recognize a three-dimensional geometrical structure on the surface of substrates, and their growth can be guided and controlled by fabricating microgrooves on substrate surfaces. ${ }^{41-44}$ The cells exhibit sensitivity to the dimensions of the microgrooves. ${ }^{45}$ Most of the microgrooves have been fabricated on inorganic substrates, such as micromachined silicon chips ${ }^{46}$ which are not very desirable for implantation. Micropatterned regions on glass coverslips with adsorbed laminin have been demonstrated to provide chemical guidance for axonal outgrowth ${ }^{47}$ (Figure 8). The magnetic alignment of positive or negative diamagnetic anisotropic molecules, such as fibrin and collagen, respectively, elicit guided in vitro regeneration and improved in vivo regeneration.
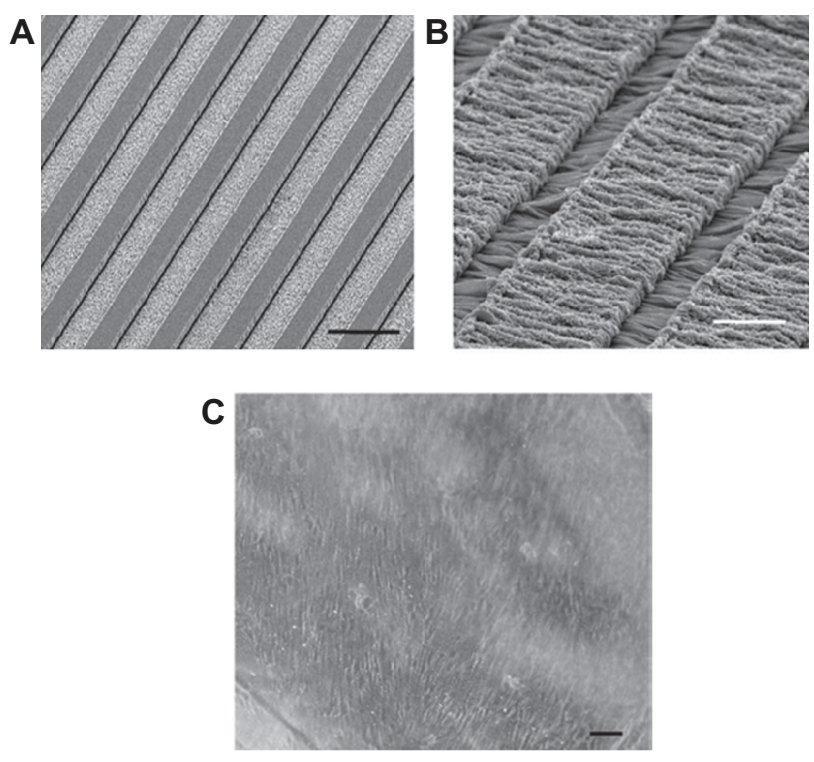

Figure 8 A, B) Schwann cells on a smooth compression-molded poly-D,L-lactic acid substrate biomaterials. C) Oriented Schwann cell growth on micropatterned biodegradable polymer substrates. 
Also, the methods are for scaffold orientation, such as magnetic fields, as discussed earlier.

\section{Nanotechnology \\ Nanometric stretch of axons}

Axons in fact are assessed based on their growth experiment with the amount of mechanical tension in the center part of the cylindrical mold. In fact, such mechanical stretches are created by bioreactor that have four main parts, ie, the expansion chamber designed for axons, linear motion table, motor, and controller (Figure 9). Axons were evaluated in conditions quite close to the ideal situation and under vacuum. The collagen gel is also used for the growth of axons although is not visible to the naked eye. Samples were evaluated by scanning electron microscopy and/or transmission electron microscopy which showed signs of growing axons. ${ }^{49} \mathrm{Also}$, it was shown that axons could sustain stretch-growth rates reaching $1 \mathrm{~cm} /$ day. However, it was unknown whether the ability to transmit active signals was maintained. It was also shown that stretch-growth did not alter sodium channel activation, inactivation, and recovery, or potassium channel activation. In addition, neurons generated normal action potentials that propagated across stretch-grown axons. Surprisingly, sodium and potassium channel density increased due to the stretch-growth, which may represent a natural response to preserve the fidelity of neuronal signaling (Figure 10). ${ }^{50}$

\section{Nanofibers}

Nanofibers are fibers with diameters one or two orders of magnitude smaller than conventional fibers. These fibers have an unusually large surface area-to-mass ratio, in the range of $10 \mathrm{~m}^{2} / \mathrm{g}$ to $1000 \mathrm{~m}^{2} / \mathrm{g}$ (when the diameter is in the order
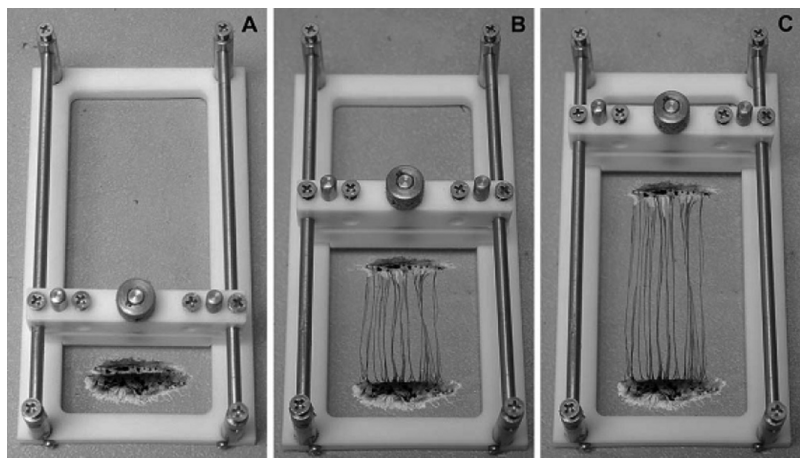

Figure 9 A schematic of axon stretch-growth. A) Neurons are plated on two adjoining substrates and are given sufficient time for axons to bridge the two substrates and integrate with neurons on both sides. B) The stretching frame displaces one population of neurons away from the other, thereby elongating the interconnecting axons. C) Axon stretch-growth is a process that can be gradually induced to achieve a rate of $\mathrm{I} \mathrm{cm} /$ day of growth and to lengths of at least $10 \mathrm{~cm}$.

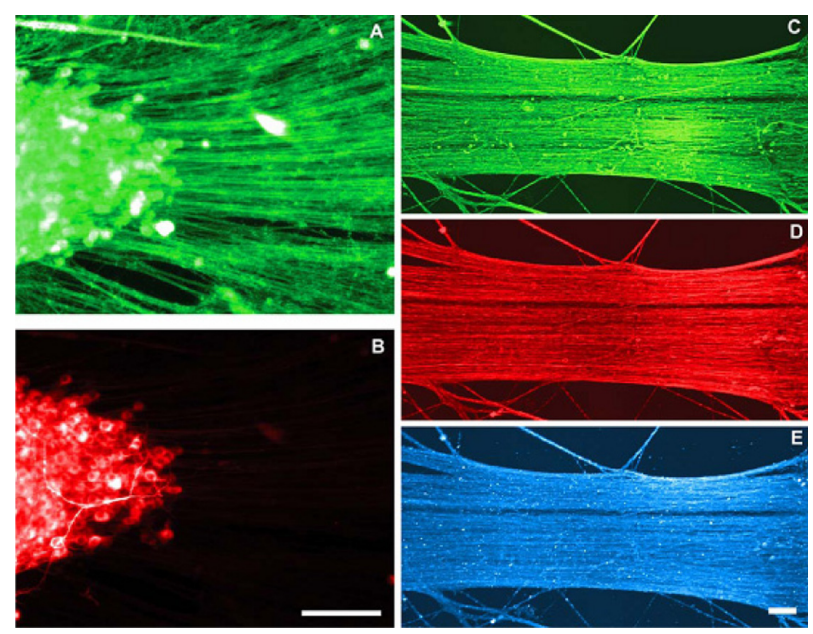

Figure 10 Immunocytochemical analysis of axon stretch-growth. A and B Antibodies against tau and MAP2 were utilized to determine that elongating processes were axons. A) The entire length of stretch-growing axons labeled positive for tau protein. B) MAP2 was labeled within the cell bodies and was void along elongating processes indicating that these processes are axons. C-E) Confocal microscopic images of axons elongated to $5 \mathrm{~cm}$ in length. Antibodies against (C)-tubulin (SMI-6I), (D) $200 \mathrm{kDa}$ phosphorylated neurofilament (SMI-3I), and (E) tau strongly labeled axons along their entire $5 \mathrm{~cm}$ of length. Scale bars: (B) $50 \mathrm{~m}$; (E).

of $500 \mathrm{~nm}$ ), which makes them suitable for a broad range of applications. ${ }^{51}$ Some nanofibers are biocompatible and biodegradable, and are used for the replacement of structurally or physiologically deficient tissues and organs in humans. The use of nanofibers in tissue restoration is expected to result in an efficient, compact organ and rapid recovery due to the large surface area offered by nanofibers made from protein, and used for wound healing, the epithelialization of implants, and the construction of biocompatible prostheses, cosmetics, face masks, bone substitutes, artificial blood vessels, valves, and drug delivery applications. ${ }^{52}$ Scaffold materials produced from nanofibers offer a large surface area that can support cell growth. Nanofibers made from silk-like proteins could improve the blood compatibility of implanted prosthetic devices by promoting in vitro and/or in vivo epithelialization of the device, thus diminishing its thrombogenic and immunogenic properties.

Nanofibers are fibers that are less than 1/1000th the diameter of a human hair. Their applications are wide-ranging in industries including aerospace, filtration, biomedical applications, and biotechnology. Nanotechnology has the potential to revolutionize many areas such as surface microscopy, silicon fabrication, biochemistry, molecular biology, physical chemistry, and computational engineering, as well as raising awareness of nanotechnology in academia, industry, and among the general public. The creation of materials and devices at the nanoscale offers unique benefits, including: 
- Increased catalytic efficiency, as a result of high surfaceto-volume ratios

- Increased material strength and hardness, due to fewer physical defects - a corollary of the assembly of nanoscale structures

- Multiple benefits related to small physical dimensions

- Faster speeds and improved energy efficiency due to higher packing densities

- Placement of devices into small structures including biologic materials such as cells

- Novel physical, electrical, chemical, optical, and magnetic properties which are ideal for specific and unique applications.

In the pharmaceutical and medical device industries, nanomaterials and nanodevices may serve many purposes, including nanoparticles and nanospheres which enable the controlled release of therapeutic agents, antibodies, genes, and vaccines into target cells, biocompatible materials to be used in prosthetics and implantable devices, fluorescent probes for monitoring biochemical processes, and sensor technologies for the detection and analysis of biologically relevant targets.

Linear aliphatic polyesters such as polyglycolide, polylactide, and copolymer poly glycolide-co-lactide are often used as the base materials for implant devices, such as suture fibers and scaffolds for tissue engineering. ${ }^{53-55}$ These materials meet several controlled-release criteria, ie, they are biocompatible and biodegradable and they can provide a high efficiency of drug loading. Many different techniques have been developed to produce nanostructured biodegradable materials such as microspheres, foams, and films. It has been demonstrated that the molecular structure and morphology of polyglycolide, polylactide, and their copolymers can play a major role in the degradation and mechanical properties of the final products. ${ }^{56-62}$ The area of research where nanotechnology has had an influence in neural tissue engineering is in developing scaffolds which help in regeneration of damaged nerves. Due to the complex physiology of regenerating nervous tissue, the scaffolds for regeneration require features that aid in the proliferation, differentiation, and migration of neuronal and glial cells. Thus, three-dimensional scaffolds, which mimic the complex physiologic properties and chemical cues of the extracellular matrix, and which enable the guided cell and axonal migration in vitro and in vivo, are necessary.

These scaffolds also need to provide a viable environment for cell growth, not elicit any immune responses, have a high surface area to allow for the movement of nutrients, and to provide strong support, while being able to degrade at a rate equal to or slower than the rate of regeneration. ${ }^{63}$ Nanoscale control over molecular assembly and topography provides the ability to introduce some of the above features with spatial and temporal control, potentially impacting nerve guidance strategies significantly. Three important characteristics of scaffolds that promote nerve regeneration include biocompatibility, degradability, and porosity. In addition, as discussed earlier, spatiotemporally controlled presentation of topographic and biochemical cues, enabled by nanoscale patterning techniques, can significantly influence regeneration, as described below.

\section{Topographical cues for regenerating nerves: natural fibers}

Natural fibers can be formed from materials such as amphiphilic molecules, silk, and collagen. The inherent properties of fiber-based materials make them highly biocompatible, and give them permeability and a compliant nature. In particular, permeability allows for the diffusion of essential nutrients that enhance the adhesion and migration of cells. However, these similar properties make the production of such fibers complex and also, the orientation of fiber for guiding cell migration is hard to control. ${ }^{63}$

\section{Self-assembling peptide nanofibers}

Natural fibers can be formed by fabrication of peptidebased amphiphilic molecules. These molecules exist in solution and then self-assemble when introduced to suspensions of cells. ${ }^{64}$ Forces from ionic bonding, hydrogen bonding, van der Waals interactions, and hydrophobic responses drive the formation of the peptide self-assembly process and generate a gel-like solid. ${ }^{64}$ The hydrophilic heads of the amphiphilic molecules can be designed to include specific epitopes. For example, the incorporation of the sequence isoleucine-lysine-valine-alanine-valine (IKVAV) can help promote neurite growth. ${ }^{65}$ Nanofibers with built-in IKVAV are $5-8 \mathrm{~nm}$ in diameter and range from hundreds of nanometers to a couple of micrometers in length. When compared with laminin and poly(D-lysine) substrates, cells cultured on IKVAV nanofibers are differentiated more quickly. Additionally, these nanofibers perform better than the coatings of IKVAV soluble peptides, because the nanofibers provide a higher density of epitopes. ${ }^{64}$ Thus, these fibers, with incorporation of specific epitopes into nanofibers, are shown to aid in neuronal differentiation. Peptide-amphiphile nanofibers can also 
be produced through soft lithography. In this process, a stamp of the fiber orientation is created and then pressed upon a solution of peptide-amphiphilic molecules. ${ }^{66}$ This arrangement is then evaporated, sonicated, and dried to produce aligned nanofibers. The dimensions of the fibers depend on the percent weight of peptide amphiphiles. For the $5 \mathrm{wt} \%$ peptide solution, the fibers produced have a width of 200-300 nm with a height of about $55.1 \mathrm{~nm}$, while the $1 \mathrm{wt} \%$ solution produced fibers with a width of $150 \mathrm{~nm}$ and a height of $23.1 \mathrm{~nm} .{ }^{66}$ However, they have only been shown to be compatible with media, and further studies need to be done with cell cultures to determine their effects better.

\section{Silk fibers to enhance nerve regeneration}

Silk fibers represent another class of natural fibers that have been used to promote nerve regeneration. After the removal of harmful materials causing adverse immunologic responses, the silk is extracted to produce fibers that are $15 \mathrm{~nm}$ in diameter. Their effects on dorsal root ganglia and Schwann cells show their biocompatibility and ability to promote cell growth. ${ }^{67,68}$ Two types of fibers have been found, including spider silk fibers and silk worm fibers for tissue reconstruction in tissue engineering, particularly in nerve tissue engineering applications. In addition to adhesion, they are able to support cell migration and are biocompatible and biodegradable; however, their tedious extraction method is a major limitation. ${ }^{69}$

Spider silk fibers increase cell adhesion and proliferation. Allmeling et al showed that nerve cells are connected rapidly and quickly to silk fibers, and grow on the silk fiber in a bipolar net with normal speed. ${ }^{69}$ These researchers used spider silk fibers for nerve regeneration.

Attempts have been made to design different scaffolds and also to synthesize these kinds of fibers. As mentioned earlier, the silk worm is another source of silk. The protein obtained from the Bombyx silk worm has a core of fibroin with a cover of sericin. Fibroin is a protein with many chains comprising a repetitive series of hydrophobic and crystal in the face of gly-ala-gly-ala-gly-x which $\mathrm{x}$ can be ser or tyr. Sericin has many roots (acid amine) pillars and is more hydrophobic. Silk fibers are so long that thay can be used on the basis of their mechanical resistance and flexibility and of course the rate of their permeability is considered in front of water and oxygen. Moreover, silk fibroin can be easily prepared and sterilized, this silk characteristic is possible to show a series of unsuitable actions. Earlier studies were done in the field of this problem and the result has indicated backgrounds of the effectiveness of sericin. On the basis of this observation, it can be said that the silk without sericin has many medical applications. So, the deletion of sericin from around the fibroein is needed before the use of silk. One useful way for its deletion is called degrumming. In this method, the solution of $\mathrm{Co}_{3} \mathrm{Na}_{2}$ which is boiled for deleting sericin has been used without damage to fibroin. Yang et al showed that the silk fibroin and the fibroin fibers derived from the solution had good biologic compatibility with cells without cytotoxic effects. ${ }^{67,68}$ Allmeling et al showed that spider silk fibers can be used as an innovative material in a biocompatible artificial nerve conduit. ${ }^{69}$

\section{Magnetically-aligned nanofibers for cell alignment}

Collagen is commonly used because it is a natural component of the extracellular matrix, providing structural strength through fibrous networks. Collagen can also be magnetically treated to produce a gel rod of aligned collagen fibrils. In strong magnetic fields, a high degree of collagen alignment is produced. This was shown through a comparison of collagen gel produced in a magnetic field of $4.7 \mathrm{~T}$ and $9.4 \mathrm{~T}$ (Figure 11). ${ }^{70}$ As a result, when seeded with dorsal root ganglia, this alignment facilitated oriented neurite extension. When combined with Schwann cells, directed migration occurred and was further enhanced in the presence of $10 \%$ fetal bovine serum. ${ }^{70}$ These data suggest that aligned collagen fibers are promising candidates as substrates for guided nerve regeneration.

\section{Biosynthetic and synthetic fibers}

Biosynthetic and synthetic fibers can be created through a variety of processes, including extrusion and electrospinning. While naturally derived polymers including collagen, elastin, and gelatin would be useful starting materials for fabrication of oriented substrates for nerve regeneration, they present technical challenges from a fabrication perspective. One solution may be to mix natural materials with synthetic polymer solutions. To electrospin a fiber, a difference in voltage is used to propel polymer fibers to a target fiber that can have functional groups which can be exploited to aid in cell adhesion. ${ }^{63}$

Furthermore, these aligned fibers guide glial alignment and promote directed growth. Like natural fibers, most biosynthetic materials are hard to fabricate due to their inherent properties, while synthetic fibers are the least problematic to produce, and it can be said that electrospinning 

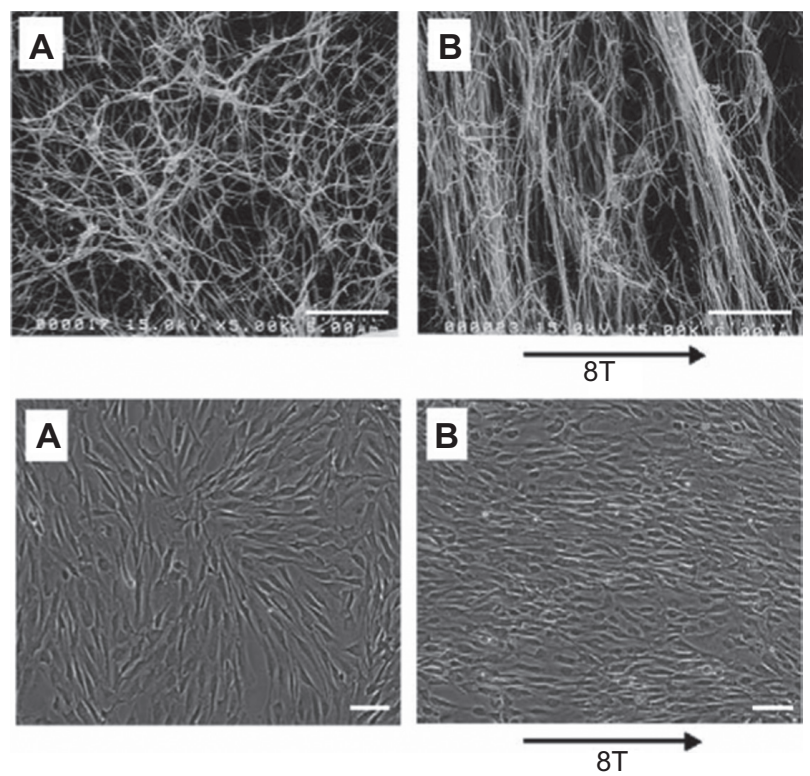

Figure I I Selected approaches for oriented scaffolds/matrices for peripheral nerve repair. Magnetically aligned structures have so far been demonstrated with collagen. Scanning electron micrographs of collagen with and without 8-T magnetic field exposure for two hours. The diameter of collagen fibril is about $100 \mathrm{~nm}$. A) Control group. B) Exposed group. Scale bars: $5 \mathrm{~mm}$. Light micrographs of Schwann cells cultured for 60 hours with and without 8-T magnetic field exposure. A) Control group. B) Exposed group. Scale bars: $100 \mathrm{~mm}$.

is one of the best and novel methods for production of nanofibrous polymers.

\section{Electrospinning}

Electrospinning is a process by which polymer nanofibers (with a diameter less than $100 \mathrm{~nm}$ and lengths reaching meters) can be produced using an electrostatically-driven jet of polymer solution. Significant progress has been made in this area over the past few years and this technology has been exploited for a wide range of applications. Most of the recent research on electrospinning has focused either on trying to understand deeper changes to many fundamental aspects of the process in order to gain control of nanofiber morphology, structure, surface functionality, and strategies for assembling them, or for determining appropriate conditions for electrospinning various polymers and biopolymers. The electrospun nanofibers can even be aligned to construct unique functional nanostructures such as nanotubes and nanowires. ${ }^{72}$ Furthermore, depending on the specific polymer being used, a wide range of fabric properties, such as strength, weight, and porosity, surface functionality can be achieved. This novel fiber spinning technique also provides the capacity to lace together a variety of polymers, fibers, and particles to produce ultrathin layers. Small insoluble particles can be added to the polymer solution and encapsulated in the dry nanofibers. Soluble drugs or bacterial agents can be added and electrospun into nonwoven mats. Nanofibers provide a connection between the nanoscale world and the macroscale world, since their diameters are in the nanometer range and they are several meters in length. Therefore, the emphasis of current research is to exploit such properties and to focus on determining appropriate conditions for electrospinning various polymers and biopolymers for eventual applications including multifunctional membranes, biomedical structural elements (scaffolds used in tissue engineering, wound dressing, drug delivery, artificial organs, vascular grafts), protective shields in specialty fabrics, filter media for submicron particles in the separation industry, composite reinforcement, and structures for nanoelectronic machines.

Interest in the electrospinning process has increased in recent years. Most of the literature on electrospinning has explored the types of polymer solvent systems from which fibers can be produced. A few studies have also addressed the processing/property relationships in electrospun polymer fibers, either directly or indirectly. Processing parameters of nanofibers have been considered with regard to applied voltage, solution-flow rate, polymer concentration, molecular weight, and the distance between the syringe needle tip-to-ground collection plate. Solution viscosity has been found to influence fiber diameter, initiating droplet shape, and the jet trajectory. Increasing solution viscosity has been associated with the production of larger diameter fibers. Baumgarten has also correlated the spinning atmosphere with the occurrence of the jet-splaying phenomena. The splaying effects have been observed by Reneker et al. Other processing variables, such as acceleration voltage, electrospinning current, and distance between the syringe needle tip-to-ground collection plate have not been investigated fully, but have been linked with fiber morphology and defect structures. The background literature for both the electrospray and electrospinning processes suggests that the structure and morphology of the final product is particles or fibers, determined by a synergistic effect of solution parameters and electrostatic forces. These parameters include viscosity, surface tension, the concentration and dielectric properties of the spinning solution, and process parameters such as the feed rate of the solution to the syringe needle tip and the acceleration voltage..$^{72,73}$ Since natural materials are difficult to spin, they can be cospun with synthetic polymers. For instance, a conductive polymer, polyaniline (PANi) can be combined with gelatin and then electrospun. Several polymer solutions with varying amounts of PANi 

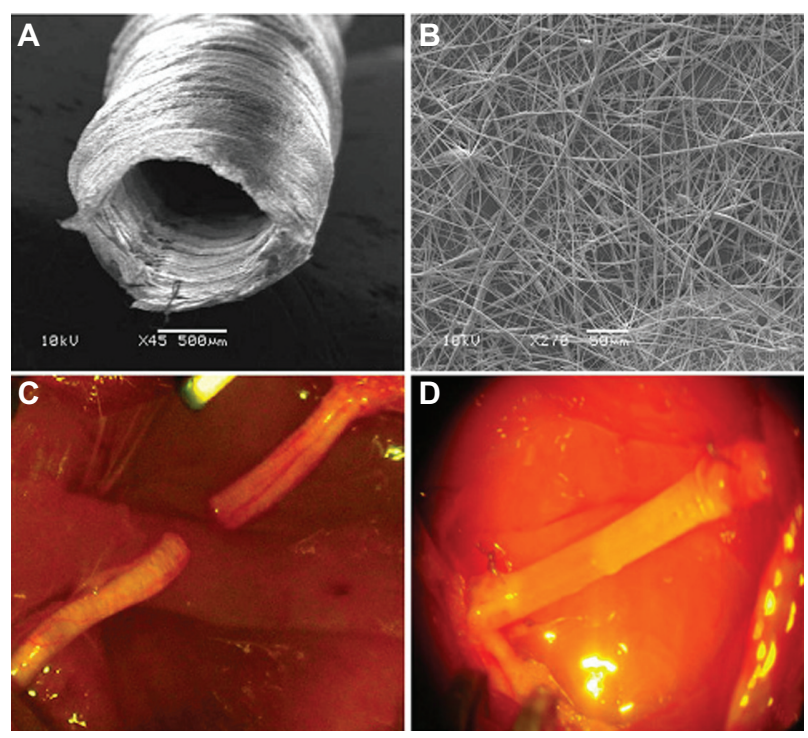

Figure 12 Experimental model. Scanning electron microscopy images of the electrospun poly-D,L-lactic acid/polycaprolactone nerve guide conduit (A) and magnified details of the tube wall (B) microfibers and nanofibers range in diameter from approximately $280 \mathrm{~nm}$ to $8 \mu \mathrm{m}$. The nonwoven fibrous microstructure is characterized by small pores $(700 \mathrm{~nm})$ and large pores $(20 \mu \mathrm{m})$. C) Micrograph of sham-operated rat sciatic nerve (experimental Group I). D) Micrograph of prosthesis implanted, filled with saline solution, and sutured to the transected nerve (experimental Group 3).

were produced, and their fibers ranged from $924 \mathrm{~nm}$ to $48 \mathrm{~nm}$ in size. The solutions with higher concentrations of PANi produced thinner fibers. Additionally, the proportion of gelatin in the solution should not be less than $5 \%$ due to the possibility of beads forming on the fibers. These fibers were then seeded with $\mathrm{H} 9 \mathrm{c} 2$ rat cardiac myoblasts, and the cells were shown to proliferate. ${ }^{76}$ Interestingly, when the width of the fiber was greater than $500 \mathrm{~nm}$, cell alignment was induced. These properties of biocompatibility and conductivity show promise for future implementation in nanofiber scaffolds.

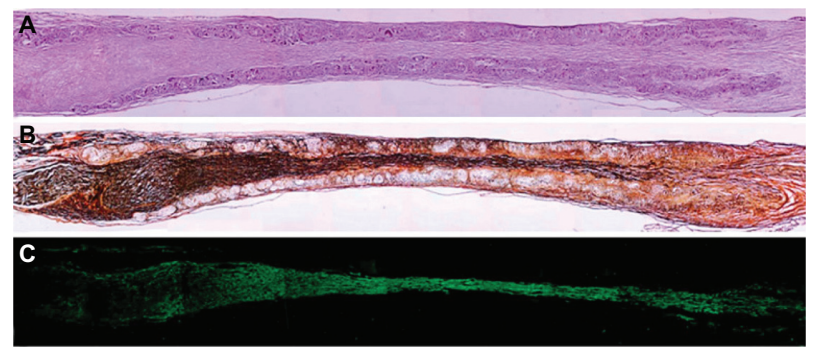

Figure 13 Longitudinal sections of nerve regenerated within the implanted guide channel. In the conduit, the regenerated nerve bridged the $10 \mathrm{~mm}$ gap, reconnecting the two sciatic nerve stumps. (A) Four months after surgery, hematoxilyn and eosin staining shows the presence of regenerated tissue filling the conduit lumen; decreased lumen diameter is observable at middle length of the guidance channel. Regenerated tissue positive to Bielschowsky staining (B) and to anti- $\beta$-tubulin antibody (C) shows nervous projections oriented along the major axis of the prosthesis bridging the $10 \mathrm{~mm}$ gap between the severed sciatic nerve stumps (image sequence collected at $4 \times$ magnification).
The most widespread synthetic polymers in neural tissue engineering are poly(a-hydroxy esters) which include PGA, PLA, and a copolymer of the two PLGA. These synthetic polymers are frequently used due to their advantageous biodegradable properties and their ease of electrospinning. ${ }^{74,75}$ Another member, PCL, is also used when a slower rate of degradation is desired, especially in some drug delivery applications. This method has been used to design neural tubes of different materials like natural polymers of chitosan ${ }^{78}$ or synthetic polymers like PLGA. ${ }^{79,80}$ Various factors affect the size of these fibers. These nanofibers increase neural cell adhesion. Our results showed that composite nanofibers had a positive effect on nerve reconstruction. Figures 12 and 13 show SEM images of the electrospun PLGA/PCL nerve guide conduit and longitudinal sections of nerve regenerated within the implanted guide channel. Previous research has also shown that composite nanofibers have a positive effect on nerve resconstruction. ${ }^{77}$

\section{Conclusion}

This article has reviewed the various methods of tube design and the materials used. Utilizing biodegradable synthetic and natural polymers could be good options for nerve regeneration, and for the design and engineering of hollow tubes filled with different materials, achieving optimal porosity, pore size, morphology, and strength. Nanotechnology is able to improve the performance of the scaffold due to the size attributes that play an important role in nerve reconstruction. Employing techniques such as magnetic fields for self-assembly and the orientation of nanofibers or nerve cells, or using a controlled design could lead, by the electrospinning method, to good results in nerve reconstruction. Designing tubes composed of composite materials, including prepared natural and synthetic polymers with oriented nanofibrous structures and finally, favorable features, could be a good option to devise scaffolds for repairing tissues, especially those in the nervous system in need of reconstruction.

\section{Disclosure}

The authors report no conflict of interest in this work.

\section{References}

1. Hughes RAC. Peripheral neuropathy: Regular review. BMJ. 2002;324: 466-469.

2. Burnett MG, Zager EL. Pathophysiology of peripheral nerve injury: Brief review. Neurosurg Focus. 2004:161-167.

3. Yin Q, Kemp GJ, Frostick SP. Neurotrophins neurones and peripheral nerve regeneration. J Hand Surg Br. 1998;23:433-437. 
4. Turgut M, Geuna S. International symposium on peripheral nerve repair and regeneration and 2nd club Brunelli meeting. J Brachial Plex Periph Nerve Inj. 2010;5:5.

5. Evans GR. Peripheral nerve injury: A review and approach to tissue engineered constructs. Anat Rec. 2001;263:396-404.

6. Ghaemmaghami F, Behnamfar F, Saberi H. Immediate grafting of transected obturator nerve during radical hysterectomy. Int J Surg. 2009;7:168-169.

7. Firouzi M, Moshayedi P, Saberi H, et al. Transplantation of Schwann cells to subarachnoid space induces repair in contused rat spinal cord. Neurosci Lett. 2006;402:66-70.

8. Bain JR. Peripheral nerve allografting: Review of the literature with relevance to composite tissue transplantation. Transplant Proc. 1998; 30(6):2762-2767.

9. Godard CW, de Ruiter MD, Spinner RJ, et al. Nerve tubes for peripheral nerve repair. Neurosurg Clin N Am. 2009;1:91-105.

10. Kosaka M. Enhancement of rat peripheral nerve regeneration through artery - including silicone tubing. Exp Neurol. 1990;107:69-77.

11. Weiss P. Scientific apparatus and laboratory methods. Reunion of stumps of small nerves by tabulation instead of sutures. Science. 1941; 93:67-68.

12. Weiss P. The technology of nerve regeneration: A review. J Neurosurg. 1944;1:400-450.

13. Walton RL, Brown RE, Matory WE, et al. Autogenous vein graft repair of digital nerve defects in the finger: A retrospective clinical study. Plast Reconstr Surg. 1989;84:944-952.

14. Tang JB. Vein conduits with interposition of nerve tissue for peripheral nerve defects. J Reconstr Microsurg. 1995;11:21-26.

15. van Mier P, Lichtman JW. Regenerating muscle fibers induce directional sprouting from nearby nerve terminals: Studies in living mice. J Neurosci. 1994;14:5672-5686.

16. Norris RW, Glasby MA, Gattuso JM, et al. Peripheral nerve repair in humans using muscle autografts: A new technique. J Bone Joint Surg Br. 1988;70B:530-533.

17. Glasby MA, Gschmeissner SE, Huang CLH, et al. Degenerated muscle grafts used for peripheral nerve repair in primates. J Hand Surg. 1986; 11B:347-351.

18. Hall S. Axonal regeneration through acellular muscle grafts. J Anat. 1997;190:57-71.

19. Doolabh VB, Hertl MC, Mackinnon SE. The role of conduits in nerve repair: A review. Rev Neurosci. 1996;7:47-84.

20. Archibald SJ, Krarup C, Shefner J, et al. A collagen-based nerve guide conduit for peripheral nerve regeneration in rodents and nonhuman primates. J Comp Neurol. 1991;306:685-696.

21. Archibald SJ, Shefner J, Krarup C, et al. Monkey median nerve repaired by nerve graft or collagen nerve guide tube. J Neurosci. 1995; 15:4109-4123

22. Williams LR, Longo FM, Powell HC, et al. Spatial-temporal progress of peripheral nerve regeneration within a silicone chamber: Parameters for a bioassay. J Comp Neurol. 1983;218:460-470.

23. Danielsen N, Varon S. Characterization of neurotrophic activity in the silicone-chamber model for nerve regeneration. J Reconstr Microsurg. 1995;11:231-235.

24. Zhao Q, Dahlin LB, Kanje M, et al. Repair of the transacted rat sciatic nerve: Matrix formation within silicon tubes. Restor Neurol Neurosci. 1993;5:197-204

25. Jenq $C B$, Coggeshall RE. Nerve regeneration through holey silicone tubes. Brain Res. 1985;361:233-241.

26. Sinis N, Kraus A, Tselis N, et al. Functional recovery after implantation of artificial nerve grafts in the rat - a systematic review. J Brachial Plex Peripher Nerve Inj. 2009;4:19.

27. Khorasani MT, Mirzadeh H, Talebi A, et al. Tubular scaffold design of poly(L-lactic acid) for nerve tissue engineering: Preparation, characterization, and in vitro assay. Iran Polymer J. 2009;18: 297-306.

28. Khorasani MT, Mirzadeh H, Irani S. Comparison of fibroblast and nerve cells response on plasma treated poly (L-lactide) surface. Journal of Applied Polymer Science. 2009;112:3429-3435.
29. Wang A, Ao Q, He Q, et al. Neural stem cell affinity of chitosan and feasibility of chitosan-based porous conduits as scaffolds for nerve tissue engineering. Tsinghua Science and Technology. 2006;11:415-420.

30. Prang P, Müller R, Eljaouhari A, et al. The promotion of oriented axonal regrowth in the injured spinal cord by alginate-based anisotropic capillary hydrogels. Biomaterials. 2006;27:3560-3569.

31. Stang F, Fansa H, Wolf G, et al. Collagen nerve conduits - Assessment of biocompatibility and axonal regeneration. Biomed Mater Eng. 2005; 15:3-12.

32. Haile Y, Haastert K, Cesnulevicius K, et al. Culturing of glial and neuronal cells on polysialic acid. Biomaterials. 2007;28: 1163-1173.

33. Kiyotani T, Teramachi M, Takimoto Y, et al. Nerve regeneration across a 25-mm gap bridged by a polyglycolic acid-collagen tube: A histological and electrophysiological evaluation of regenerated nerves. Brain Res. 1996;740:66-74.

34. Prang P, Müller R, Eljaouhari A, et al. The promotion of oriented axonal regrowth in the injured spinal cord by alginate-based anisotropic capillary hydrogels. Biomaterials. 2006;27:3560-3569.

35. Wang A, Ao Q, Cao W, et al. Porous chitosan tubular scaffolds with knitted outer wall and controllable inner structure for nerve tissue engineering. J Biomed Mater Res A. 2006;79:36-46.

36. Flynn L, Dalton PD, Shoichet MS. Fiber templating of poly (2-hydroxyethyl methacrylate) for neural tissue engineering. Biomaterials. 2003;24:4265-4272.

37. Yu TT, Shoichet MS. Guided cell adhesion and outgrowth in peptidemodified channels for neural tissue engineering. Biomaterials. 2005;26:1507-1514

38. Itoh S, Yamaguchi I, Shinomiya K, et al. Development of the chitosan tube prepared from crab tendon for nerve regeneration. Science and Technology of Advanced Materials. 2003;4:261-268.

39. Newman KD, McLaughlin CR, Carlsson D, et al. Bioactive hydrogelfilament scaffolds for nerve repair and regeneration. Int J Artif Organs. 2006;29:1082-1091

40. Cai J, Peng X, Nelson KD, et al. Permeable guidance channels containing microfilament scaffolds enhance axon growth and maturation. J Biomed Mater Res A. 2005;75A:374-386.

41. Weiss P. Experiments of cell and axon orientation in vitro: The role of colloidal exudates in tissue organization. J Exp Zool. 1945;63: 401-450.

42. Turner DC, Lawson J, Dollenmeier P, et al. Guidance of myogenic cell migration by oriented deposits of bronectin. Dev Biol. 1983;95: 497-604.

43. Clark P, Connolly P, Curtis SG, et al. Topographical control of cell behaviour. I. Simple step cues. Development. 1987;99:439-448.

44. Dow JA, Clark P, Connolly P, et al. Novel methods for guidance and monitoring of single cell and simple networks in culture. J Cell Sci. 1987;8:55-79.

45. Clark P, Britland S, Connolly P. Growth cone guidance and neuron morphology on micropatterned laminin surfaces. J Cell Sci. 1993;105: 203-212.

46. Zhao Q, Drott J, Laurell T, et al. Rat sciatic nerve regeneration through micromachined silicon chip. Biomaterials. 1997;18:75-80.

47. Tai HC, Buettner HM. Neurite outgrowth and growth cone morphology on micropatterned surfaces. Biotechnol Prog. 1998; $14: 364-370$

48. Miller C, Shanks H, Witt A, et al. Oriented Schwann cell growth on micropatterned biodegradable polymer substrates. Biomaterials. 2001; 22:1263-1269.

49. Pfister BJ, Iwata A, Taylor AG, et al. Development of transplantable nervous tissue constructs comprised of stretch-grown axons. JNeurosci Methods. 2006;153:95-103.

50. Pfister BJ, Bonislawski DP, Smith DH, et al. Stretch-grown axons retain the ability to transmit active electrical signals. FEBS Lett. 2006;580:3525-3531.

51. Reneker DH, Chun I. Nanometre diameter fibres of polymer produced by electrospinning. Nanotechnology. 1996;7:216-223. 
52. Frenot A, Chronakis IS. Polymer nanofibers assembled by electrospinning. Curr Opin Colloid Interface Sci. 2003;8:64-75.

53. Langer R, Vacanti JP. Tissue engineering. Science. 1993;260: 920-926.

54. Zong X, Kim K, Fang D, et al. Structure and process relationship of electrospun bioabsorbable nanofiber membranes. Polymer. 2002;43: 4403-4412.

55. Butler SM, Tracy MA, Tilton RD. Adsorption of serum albumin to thin films of poly(lactide-co-glycolide). J Control Release. 1999;58: 335-337.

56. Dzenis Y. Spinning continuous fibers for nanotechnology. Science. 2004;304:1917-1919.

57. Huang ZM, Zhang YZ, Kotaki M, et al. A review on polymer nanofibers by electrospinning and their applications in nanocomposites. Compos Sci Technol. 2003;63:2223-2253.

58. $\mathrm{Xu} \mathrm{CY}$, Inai R, Kotaki M, et al. Aligned biodegradable nanofibrous structure: A potential scaffold for blood vessel engineering. Biomaterials. 2004;25:877-886.

59. Theron SA, Zussman E, Yarin AL. Experimental investigation of the governing parameters in the electrospinning of polymer solutions. Polymer. 2004;45:2017-2030.

60. Reneker DH, Yarin AL, Fong H, et al. Bending instability of electrically charged liquid jets of polymer solutions in electrospinning. JAppl Phys. 2000;87:4531-4547.

61. Baumgarten PK. Electrostatic spinning of acrylic microfibers. J Colloid Interface Sci. 1971;36:71-79.

62. Deitzel JM, Kleinmeyer D, Harris D, et al. The effect of processing variables on the morphology of electrospun nanofibers and textiles. Polymer. 2001;42:261-272.

63. Murugan R, Ramakrishna S. Design strategies of tissue engineering scaffolds with controlled fiber orientation. Tissue Eng. 2007;13: $1845-1866$.

64. Silva GA, Czeisler C, Niece KL, et al. Selective differentiation of neural progenitor cells by high-epitope density nanofibers. Science. 2004;303:1352-1355.

65. Silva GA. Nanotechnology approaches for the regeneration and neuroprotection of the central nervous system. Surg Neurol. 2005;63:301-306.

66. Hung AM, Stupp SI. Simultaneous self-assembly, orientation, and patterning of peptide-amphiphile nanofibers by soft lithography. Nano Lett. 2007;7:1165-1171.

67. Yang Y, Ding F, Wu J, et al. Biocompatibility evaluation of silk fibroin with peripheral nerve tissues and cells in vitro. Biomaterials. 2007;28: $1643-1652$.
68. Yang Y, Ding F, Wu J, et al. Development and evaluation of silk fibroin-based nerve grafts used for peripheral nerve regeneration. Biomaterials. 2007;28:5526-5535.

69. Allmeling C, Jokuszies A, Reimers K, et al. Use of spider silk fibres as an innovative material in a biocompatible artificial nerve conduit. J Cell Mol Med. 2006;10:770-777.

70. Dubey N, Letourneau PC, Tranquillo RT. Guided neurite elongation and Schwann cell invasion into magnetically aligned collagen in simulated peripheral nerve regeneration. Exp Neurol. 1999;158:338-350.

71. Eguchi Y, Ogiue-Ikeda M, Ueno S. Control of orientation of rat Schwann cells using an 8-T static magnetic field. Neuro Lett. 2002;351: 130-132.

72. Lannutti J, Reneker D, Ma T, Tomasko D, Farson D. Electrospinning for tissue engineering scaffolds. Materials Science and Engineering $C$. 2007;27:504-509.

73. Agarwal S, Wendorff JH, Greiner A. Use of electrospinning technique for biomedical applications. Polymer. 2008;49:5603-5621.

74. Li WJ, Cooper JA Jr, Mauck RL, et al. Fabrication and characterization of six electrospun poly(alpha-hydroxy ester)-based fibrous scaffolds for tissue engineering applications. Acta Biomater. 2006;2:377-385.

75. Li WJ, Laurencin CT, Caterson EJ, et al. Electrospun nanofibrous structure: A novel scaffold for tissue engineering. J Biomed Mater Res. 2002;60:613-621.

76. Li M, Guo Y, Wei Y, et al. Electrospinning polyaniline-contained gelatin nanofibers for tissue engineering applications. Biomaterials. 2006;27:2705-2715.

77. Panseri S, Cunha C, Lowery J, et al. Electrospun micro- and nanofiber tubes for functional nervous regeneration in sciatic nerve transections. BMC Biotechnol. 2008;8:39.

78. Wang W, Itoh S, Konno K, et al. Effects of Schwann cell alignment along the oriented electrospun chitosan nanofibers on nerve regeneration. Biomed Mater Res A. 2009;15;91:994-1005.

79. Bini TB, Gao S, Tan TC, et al. Electrospun poly(L-lactide-co-glycolide) biodegradable polymer nanofibre tubes for peripheral nerve regeneration. Nanotechnology. 2004;15:1459.

80. Prabhakaran MP, Venugopal J, Chan CK, et al. Surface modified electrospun nanofibrous scaffolds for nerve tissue engineering. Nanotechnology. 2008;19:455102.
International Journal of Nanomedicine

\section{Publish your work in this journal}

The International Journal of Nanomedicine is an international, peerreviewed journal focusing on the application of nanotechnology in diagnostics, therapeutics, and drug delivery systems throughout the biomedical field. This journal is indexed on PubMed Central, MedLine, CAS, SciSearch ${ }^{\circledR}$, Current Contents ${ }^{\circledR} /$ Clinical Medicine,

\section{Dovepress}

Journal Citation Reports/Science Edition, EMBase, Scopus and the Elsevier Bibliographic databases. The manuscript management system is completely online and includes a very quick and fair peer-review system, which is all easy to use. Visit http://www.dovepress.com/ testimonials.php to read real quotes from published authors. 